\title{
Effect of DEC1 on the proliferation, adhesion, invasion and epithelial-mesenchymal transition of osteosarcoma cells
}

\author{
SHUAI LI, DAN PENG, ZI-QING YIN, WEI ZHU, XUAN-TAO HU and CONG-WEI LIU \\ Department of Orthopaedics, The Second Xiangya Hospital of Central South University, Changsha, Hunan 410011, P.R. China
}

Received March 22, 2019; Accepted December 19, 2019

DOI: $10.3892 /$ etm.2020.8459

\begin{abstract}
Differentiated embryonic chondrocyte-expressed gene 1 (DEC1) is associated with various types of human cancer; however, there is limited data regarding the functions of DEC1 in osteosarcoma. The present study aimed to examine the expression of DEC1 in human osteosarcoma tissues and cell lines. Furthermore, the effects of DEC1 on the proliferation, adhesion, invasion and epithelial-mesenchymal transition (EMT) of osteosarcoma cells were investigated. Using reverse transcription-quantitative PCR and western blot analysis, it was found that the expression levels of DEC1 were higher in human osteosarcoma tissues and osteosarcoma cell lines than in the controls. Both gain- and loss-of-function experiments suggested that DEC1 promotes the proliferation, adhesion and invasion of osteosarcoma cells in vitro, as determined by MTT, cell adhesion and cell invasion assays, respectively. Additionally, DEC1 was found to upregulate the mesenchymal markers $\mathrm{N}$-cadherin and vimentin, whilst downregulating the epithelial marker E-cadherin. In conclusion, this present study showed increased expression levels of DEC1 in human osteosarcoma tissues and cell lines, and identified that DEC1 may exert its effect on osteosarcoma progression by promoting cell proliferation, adhesion and invasion. Furthermore, DEC1 was shown to have an inducible effect on EMT in osteosarcoma cell lines, thus contributing to the aggressiveness of osteosarcoma cells. This initial study indicated that DEC1 may serve as a novel molecular target for the treatment of osteosarcoma.
\end{abstract}

\section{Introduction}

Osteosarcoma is the most common primary malignancy of bone tissue, typically presenting in teenagers and young

Correspondence to: Professor Dan Peng, Department of Orthopaedics, The Second Xiangya Hospital of Central South University, 139 Middle Renmin Road, Changsha, Hunan 410011, P.R. China

E-mail: xyeypd@163.com

Key words: differentiated embryonic chondrocyte-expressed gene 1, osteosarcoma, proliferation, adhesion, invasion, epithelial-mesenchymal transition adults (1). This tumor has a highly invasive and distant metastatic potential $(2,3)$, and the 5-year survival rate in patients with metastatic osteosarcoma is $5-20 \%(4,5)$. Therefore, it is important to clarify the molecular mechanisms of action behind osteosarcoma metastasis and to explore effective therapeutic approaches to treat patients with osteosarcoma.

Aberrant expression and activation of transcription factors occurs frequently in various cancer types. Differentiated embryonic chondrocyte-expressed gene 1 (DEC1) is a basic helix-loop-helix transcription factor that has been detected in a variety of developing and adult tissues (6-8). DEC1 plays an important role in numerous biological events, including cell survival, differentiation, circadian rhythms and hypoxia response (9-12). Additionally, DEC1 has been reported to promote tumor progression, invasion and metastasis (13-16). Previous studies have shown that DEC1 is associated with various types of human cancers, such as lung, gastric, liver and breast cancer (17-20). Recently, Zhou et al (21) found that knockdown of cryptochrome circadian regulator 1 enhanced the proliferation and migration of osteosarcoma cells presenting downregulation of DEC1. However, there is limited data regarding the function of DEC1 in osteosarcoma.

The present study aimed to examine the expression level of DEC1 in human osteosarcoma tissues and cell lines. Furthermore, the effects of DEC1 on the proliferation, adhesion, invasion and epithelial-mesenchymal transition (EMT) of osteosarcoma cells were investigated.

\section{Materials and methods}

Tissue collection. A total of 21 osteosarcoma patients were recruited for this study from January 2014 to May 2018 (12-25 years old; 11 males and 10 females). All patients provided written informed consent in compliance with the code of ethics of the World Medical Association (Declaration of Helsinki). The present study was approved by the Ethics Committee of The Second Xiangya Hospital of Central South University. The human osteosarcoma samples and adjacent normal tissues (located $>3 \mathrm{~cm}$ away from the tumor) were collected from the patients who underwent surgery at The Second Xiangya Hospital of Central South University. The tissue samples were frozen in liquid nitrogen prior to experimentation.

Cell culture and transfection. hFOB, MG63, Saos-2 and U2OS cells were purchased from the American Type Culture Collection 
and maintained in DMEM (Gibco; Thermo Fisher Scientific, Inc.), supplemented with 10\% FBS (Gibco; Thermo Fisher Scientific, Inc.). All cells were incubated at $37^{\circ} \mathrm{C}$ in a humidified atmosphere of $5 \% \mathrm{CO}_{2}$. Prior to transfection, the cells were washed with PBS, and the medium was replaced with serum-free DMEM. A total of $200 \mathrm{ng}$ small interfering (si)RNA control (siControl; forwards, 5'-UUCUCCGAACGUGUCACGUTT-3' and reverse, 5'-ACGUGACACGUUCGGAGAATT-3'; Shanghai GenePharma Co., Ltd.), DEC1 siRNA (forwards, 5'-GAACAU CUCAAACUUACAACUTT-3' and reverse, 5'-AGUUGUAAG UUUGAGAUGUUCTT-3'; Shanghai GenePharma Co., Ltd.), empty plasmid (pcDNA3.1; Shanghai GenePharma Co., Ltd.) or DEC1 overexpression plasmid (Shanghai GenePharma Co., Ltd.) was transfected into the cells using Lipofectamine ${ }^{\circledR} 2000$ (Invitrogen; Thermo Fisher Scientific, Inc.) according to the manufacturer's instructions. After $6 \mathrm{~h}$, the medium was replaced with fresh medium and the cells were maintained in the culture flasks for at least $24 \mathrm{~h}$ prior to subsequent analysis.

Reverse transcription-quantitative PCR (RT-qPCR). Total RNA was extracted from the tissues and cells using Trizol ${ }^{\circledR}$ (Invitrogen; Thermo Fisher Scientific, Inc.) following the manufacturer's instructions. cDNA was reverse transcribed using a First Strand cDNA Synthesis kit (Fermentas; Thermo Fisher Scientific, Inc.) at $42^{\circ} \mathrm{C}$. qPCR was performed on an ABI 7300 real-time PCR system using a SYBR Green PCR kit (Applied Biosystems). The primers used for amplification were as follows: DEC1 forward, 5'-GAAAGGATCGGCGCAATT AA-3', and reverse, 5'-CATCATCCGAAAGCTGCATC-3'; GAPDH forward, 5'-CGACCACTTTGTCAAGCTCA-3', and reverse, 5'-AGGGGTCTACATGGCAACTG-3'. GAPDH was used as a control. Primers were used at a final concentration of $250 \mathrm{nM}$. The reaction was followed by 40 cycles at $95^{\circ} \mathrm{C}$ for $30 \mathrm{sec}, 58^{\circ} \mathrm{C}$ for $30 \mathrm{sec}$ and $72^{\circ} \mathrm{C}$ for $30 \mathrm{sec}$. mRNA levels were quantified using the $2^{-\Delta \Delta \mathrm{Cq}}$ relative quantification method (22).

Western blot analysis. Total protein was extracted from the tissues and cells using RIPA buffer (Elabscience Biotechnology Co., Ltd.). Protein concentration was determined using a Bicinchoninic Acid protein assay. Equal amounts of total protein $(50 \mu \mathrm{g})$ were separated on a $12 \%$ sodium dodecyl sulfate polyacrylamide gel using electrophoresis, and then transferred onto a nitrocellulose membrane (EMD Millipore). The membranes were blocked with $3 \%$ bovine serum albumin (Sigma-Aldrich; Merck KGaA) at $4^{\circ} \mathrm{C}$ overnight and were subsequently subjected to 3 washes with Tris-buffered saline and Tween-20 (0.05\%) (TBST). The membranes were incubated with the primary antibodies, including DEC1 mouse monoclonal antibody (sc-101023; 1:500; Santa Cruz Biotechnology, Inc.), E-cadherin mouse monoclonal antibody (sc-71007; 1:400; Santa Cruz Biotechnology, Inc.), N-cadherin mouse monoclonal antibody (sc-8424; 1:400; Santa Cruz Biotechnology, Inc.), vimentin mouse monoclonal antibody (sc-66002; 1:800; Santa Cruz Biotechnology, Inc.) and GAPDH mouse monoclonal antibody (sc-47724; 1:1,000; Santa Cruz Biotechnology, Inc.) at $37^{\circ} \mathrm{C}$ for $1 \mathrm{~h}$. The membranes were washed with TBST and incubated with horseradish peroxidase-labeled goat anti-mouse secondary antibody (sc-2005; dilution, 1:2,000; Santa Cruz Biotechnology, Inc.) at $37^{\circ} \mathrm{C}$ for $1 \mathrm{~h}$. The chemiluminescent signal was detected using an enhanced chemiluminescence detection kit (Pierce; Thermo Fisher Scientific, Inc.). Image-Pro Plus software (version 6.0; Media Cybernetics, Inc.) was used for densitometry analysis.

MTT assay. Cell proliferation was determined using MTT assays. The cells were seeded into 96-well plates, allowed to grow for 24, 48, 72 and $96 \mathrm{~h}$, and then incubated with $10 \mu \mathrm{l}$ MTT (Sigma-Aldrich; Merck KGaA) at $37^{\circ} \mathrm{C}$ for $4 \mathrm{~h}$. A total of $200 \mu 1$ DMSO (Sigma-Aldrich; Merck KGaA) was added to solubilize the formazan crystals. The absorbance at $570 \mathrm{~nm}$ was then measured using a microplate reader (SpectraMax 190; Molecular Devices, LLC).

Cell adhesion assay. For the cell adhesion assays, 96-well plates were pre-coated with fibronectin (Sigma-Aldrich; Merck $\mathrm{KGaA}$ ) and blocked with $1 \% \mathrm{BSA}$ at $37^{\circ} \mathrm{C}$ for $2 \mathrm{~h}$. Cells in serum-free medium were seeded into the 96 -well plates at the density of $2 \times 10^{5}$ cells $/ \mathrm{ml}(0.2 \mathrm{ml})$ and incubated at $37^{\circ} \mathrm{C}$ for $2 \mathrm{~h}$. The adhesive cells were then fixed in $4 \%$ paraformaldehyde at room temperature for $30 \mathrm{~min}$ and stained with $0.5 \%$ crystal violet (Sangon Biotech, Co. Ltd.) at room temperature for $2 \mathrm{~h}$. SDS (Amresco LLC) was used to dissolve the crystals. The absorbance at $570 \mathrm{~nm}$ was measured using a microplate reader.

Cell invasion assay. Transwell inserts (Corning, Inc.) were coated with Matrigel matrix (BD Biosciences) at $37^{\circ} \mathrm{C}$ for $30 \mathrm{~min}$. Cell suspensions were prepared in serum-free medium at a final concentration of $5 \times 10^{4} \mathrm{cells} / \mathrm{ml}$ and added to the upper chambers. Subsequently, $1 \mathrm{ml}$ of $10 \%$ FBS-containing medium was added to the lower chambers. Following incubation at $37^{\circ} \mathrm{C}$ overnight, a cotton swab was used to remove non-invasive cells. The cells on the lower surface of the membrane were fixed using $95 \%$ ethanol for $20 \mathrm{~min}$ and stained with hematoxylin for $10 \mathrm{~min}$ at room temperature. The number of invaded cells was counted using an inverted light microscope (TS100; Nikon Corporation).

Statistical analysis. All data are expressed as the means \pm SD from at least three independent experiments. Statistical analysis was performed using GraphPad Prism Software (version 5; GraphPad Software, Inc.). Differences between two groups were assessed by the paired Student's t-test, and ANOVAs followed by student-Keuls-Newman tests were used to compare the differences between three or more groups. $\mathrm{P}<0.05$ was considered to indicate a statistically significant difference.

\section{Results}

Expression of DECl in human osteosarcoma tissues and cell lines. A total of 21 human osteosarcoma specimens and adjacent non-tumor tissues were collected to investigate DEC1 expression using RT-qPCR and western blot analysis. It was found that the expression levels of DEC1 mRNA and DEC1 protein were higher in human osteosarcoma tissues compared with adjacent non-tumor tissues (Fig. 1A). DEC1 expression was also analyzed in a normal bone cell line (hFOB) and in osteosarcoma cell lines (MG63, U2OS and Saos-2). As shown in Fig. 1B, the expression levels of DEC1 mRNA and DEC1 protein were higher in osteosarcoma cells than in normal bone cells. 

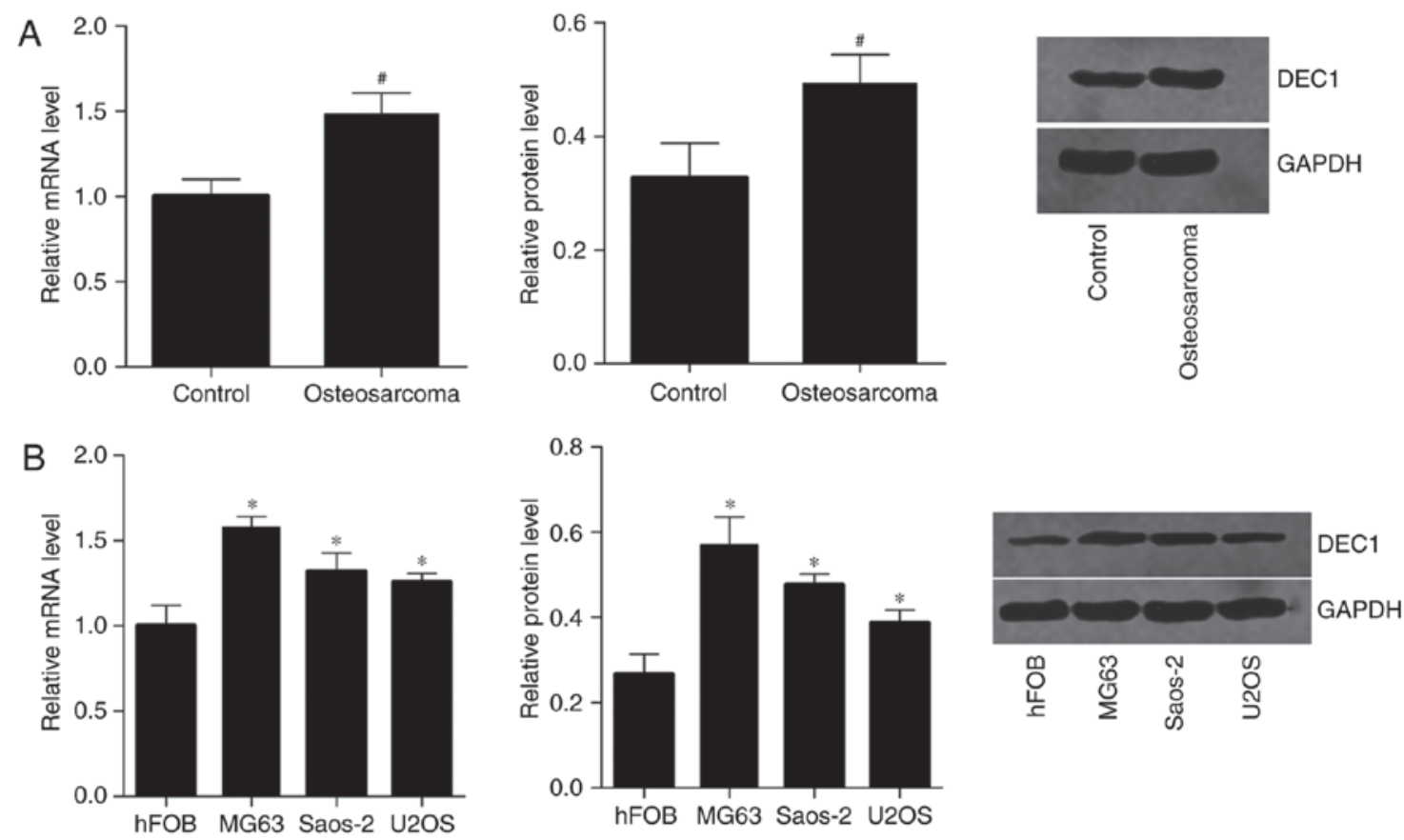

Figure 1. Expression of DEC1 in human osteosarcoma tissue samples and cell lines. (A) mRNA and protein expression levels of DEC1 in human osteosarcoma tissues and the adjacent non-tumor tissues. ${ }^{~} \mathrm{P}<0.01$ vs. control group. (B) Expression of DEC1 mRNA and protein in the normal bone cell line, $\mathrm{hFOB}$ and osteosarcoma cell lines, MG63, U2OS and Saos-2. "P<0.05 vs. hFOB. DEC1, differentiated embryonic chondrocyte-expressed gene 1.

A

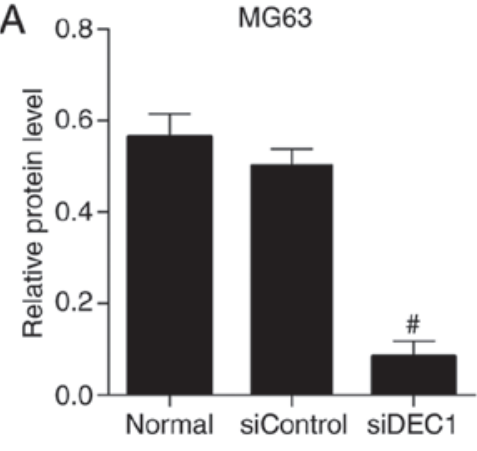

U20S

B

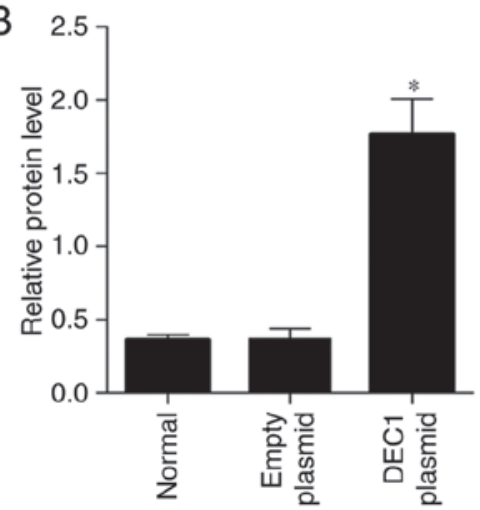

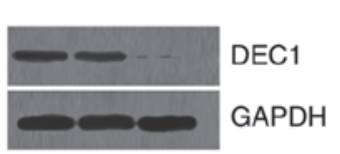
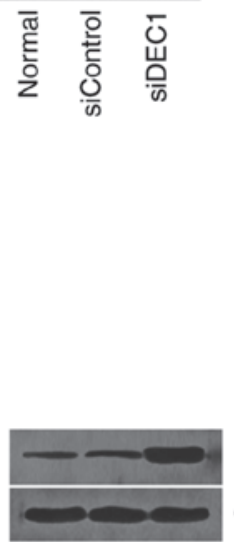

DEC1 GAPDH

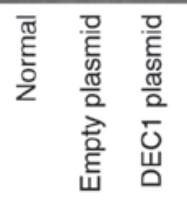

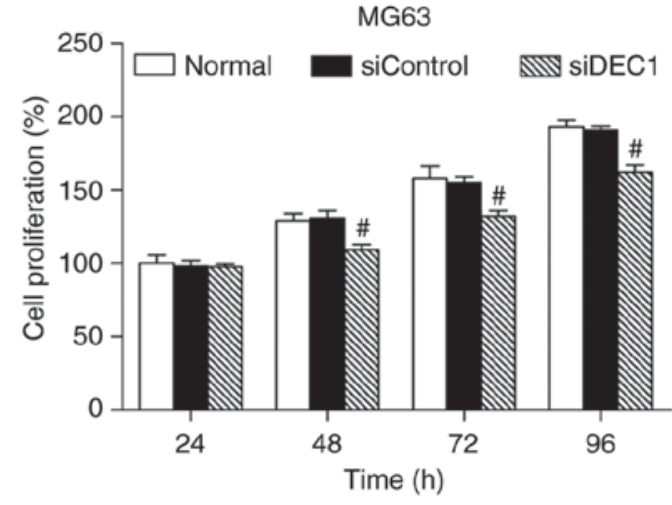

U20S

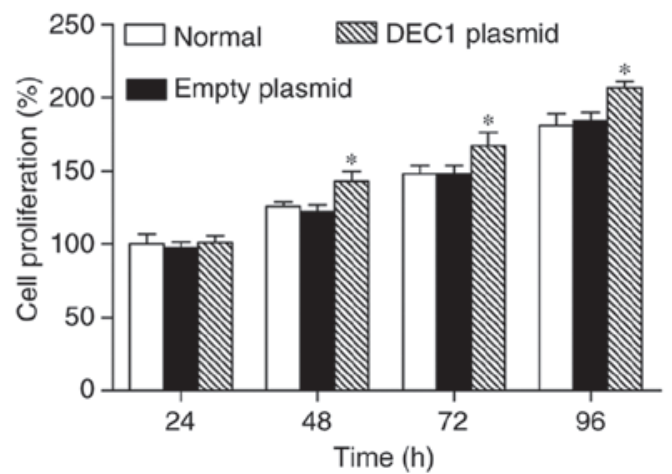

Figure 2. Effect of DEC1 on osteosarcoma cell proliferation. (A) Expression levels of DEC1 protein in MG63 cells transfected with siDEC1, and the effect of siDEC1 on cell proliferation. "P<0.01 vs. siControl. (B) Expression of DEC1 protein in U2OS cells transfected with the DEC1 plasmid, and the effect of DEC1 plasmid on cell proliferation. " $\mathrm{P}<0.05$ vs. empty plasmid. DEC1, differentiated embryonic chondrocyte-expressed gene 1; si, small interfering RNA.

Effect of DECl on the proliferation of osteosarcoma cells. To investigate the biological functions of DEC1 in osteosarcoma cells, both gain- and loss-of-function experiments were performed in vitro. MG63 cells with endogenously high DEC1 

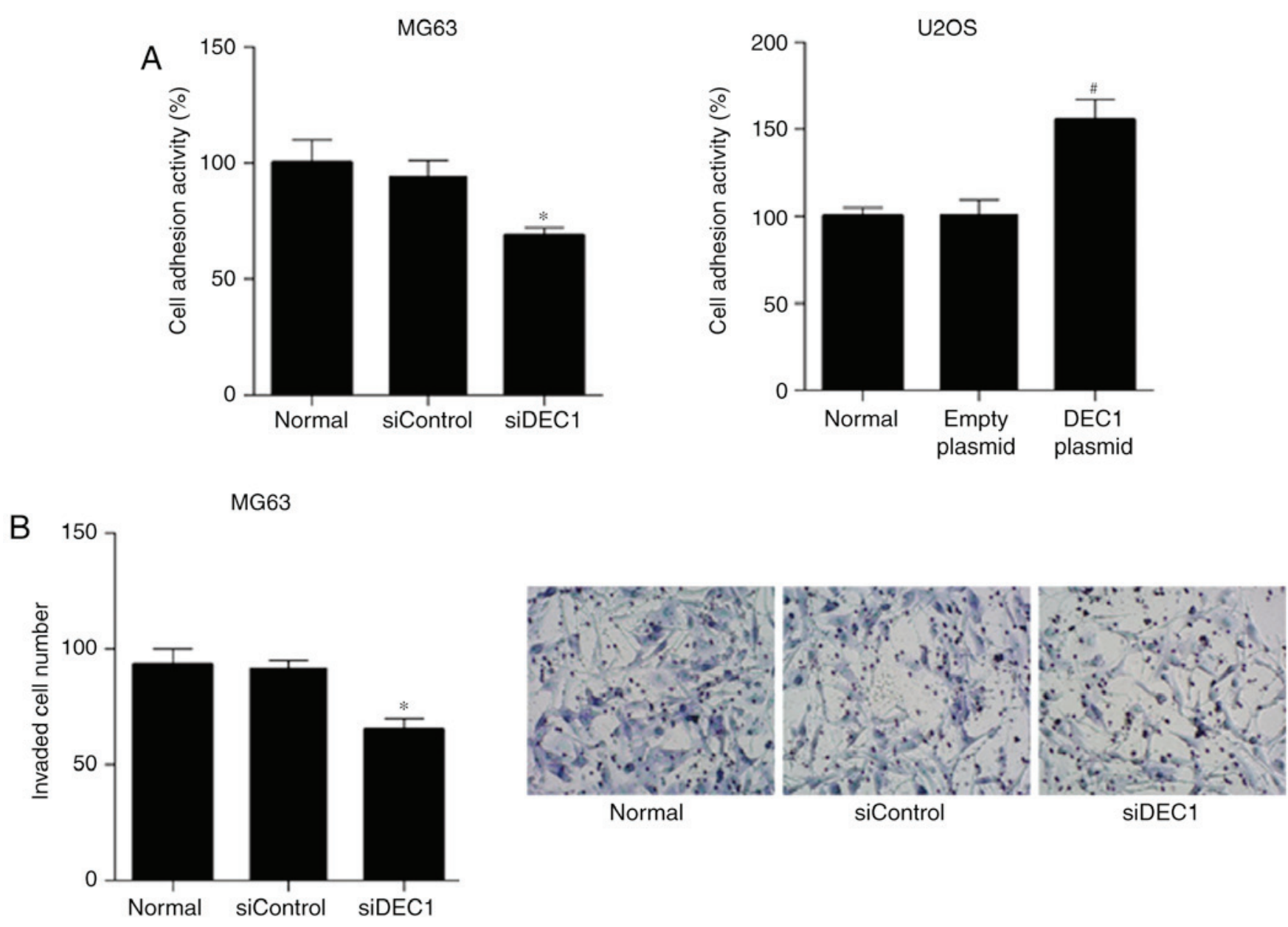

U2OS

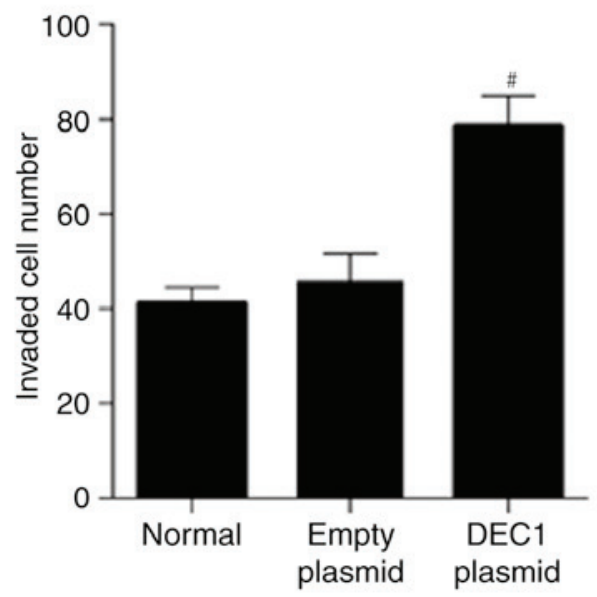

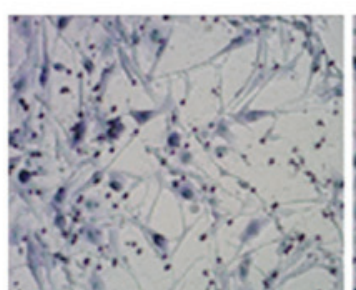

Normal

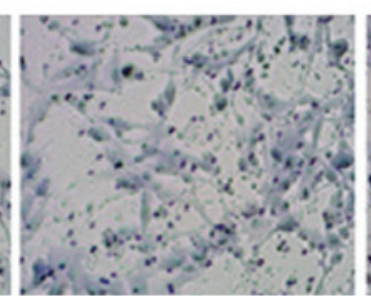

Empty plasmid

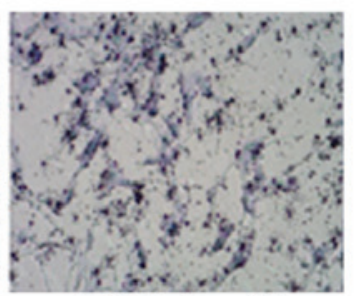

DEC1 plasmid

Figure 3. Effect of DEC1 on osteosarcoma cells adhesion and invasion. (A) Adhesion and (B) invasion have been investigated. * $\mathrm{P}<0.05$ vs. siControl. ${ }^{\#} \mathrm{P}<0.01$ vs. empty plasmid. DEC1, differentiated embryonic chondrocyte-expressed gene 1; si, small interfering RNA.

expression were selected to be transfected with DEC1 siRNA, in order to knockdown DEC1. In contrast, U2OS cells with endogenously low DEC1 expression were selected to be transfected with the DEC1 plasmid, in order to overexpress DEC1. Subsequently, the effect of DEC1 on osteosarcoma cells proliferation was examined using MTT assays. The present results showed that DEC1 overexpression significantly promoted the proliferation of U2OS cells, while DEC1 knockdown significantly inhibited the proliferation of MG63 cells (Fig. 2).
Effect of DECl on the adhesion and invasion of osteosarcoma cells. To investigate the effects of DEC1 on the adhesive and invasive capabilities of osteosarcoma cells, cell adhesion and invasion experiments were performed in vitro. The present results showed that MG63 cells transfected with DEC1 siRNA had a reduced adhesive and invasive ability compared with those cells transfected with siControl. Overexpression of $\mathrm{DEC1}$ increased the adhesive and invasive abilities of U2OS cells (Fig. 3). 

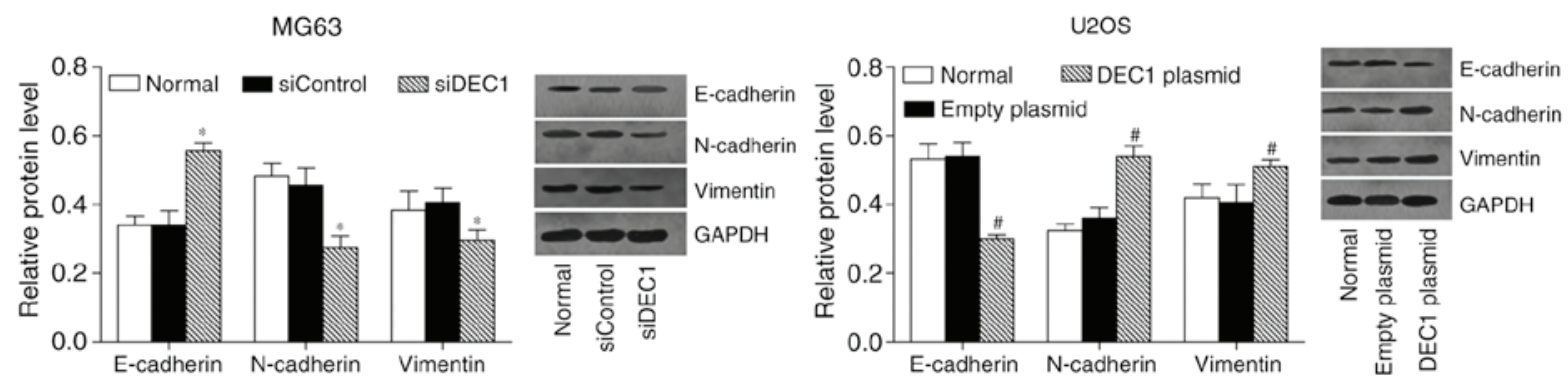

Figure 4. Effect of DEC1 on the epithelial-mesenchymal transition in osteosarcoma cells. ${ }^{*} \mathrm{P}<0.05$ vs. siControl. ${ }^{*} \mathrm{P}<0.01$ vs. empty plasmid. DEC1, differentiated embryonic chondrocyte-expressed gene 1; si, small interfering.

Effect of DEC1 on the EMT in osteosarcoma cells. To evaluate whether DEC1 regulates EMT in osteosarcoma cells, the expression levels of EMT-related proteins, including E-cadherin, $\mathrm{N}$-cadherin and vimentin were examined. As demonstrated by western blot analysis, DEC1 overexpression significantly upregulated $\mathrm{N}$-cadherin and vimentin but downregulated E-cadherin in U2OS cells, whereas knockdown of DEC1 produced the opposite results in MG63 cells (Fig. 4).

\section{Discussion}

Dysregulated expression of DEC1 has been observed in a number of types of human cancer. Upregulated DEC1 has been found in gastric, liver, pancreatic and breast cancer $(6,13,15,23-27)$. Downregulated DEC1 has been found in non-small cell lung cancer $(17,28)$. However, the expression of DEC1 in osteosarcoma has not been previously reported. In the present study, DEC1 expression levels in human osteosarcoma tissues and cell lines were examined, and it was found that osteosarcoma tissues and osteosarcoma cells had higher expression levels of DEC1 compared with the controls. The present findings suggested DEC1 is aberrantly expressed in osteosarcoma, and the present results indicated that DEC1 may be involved in the progression of osteosarcoma.

DEC1 has multifaceted roles in cancer progression (8). A previous study has shown that downregulation of DEC1 inhibits gastric cancer cell proliferation in vitro and tumorigenicity in vivo (18). DEC1 is upregulated by TGF- $\beta$ in PANC-1 cells, and regulates the expression of EMT-related factors. DEC1 knockdown inhibits morphological changes during EMT processes (13). Li et al reported that DEC1 induces the activation of apoptosis-related factor, survivin, under serum-starvation, which has an anti-apoptotic effect in HEK293 cells (29). In contrast, Thin et al found that DEC1 is induced in response to several DNA-damaging agents and has a pro-apoptotic effect (30). Additionally, it has been reported that high levels of DEC1 inhibit cell proliferation and colony formation of esophageal squamous cell carcinoma cells, promoting cellular senescence (16). The complex mechanisms underlying the role of DEC1 in carcinogenesis are controversial. However, all these findings suggest that aberrant expression levels of DEC1 play important roles in tumor progression. Currently, there are no reports into the role of DEC1 in osteosarcoma. Proliferation and metastasis are critical events in the pathogenesis of cancer (31). Using the osteosarcoma cell lines MG63 and U2OS, this study found that
DEC1 knockdown inhibits the proliferation of osteosarcoma cell lines and DEC1 overexpression promotes cell proliferation in vitro. Furthermore, the effect of DEC1 on the adhesive and invasive abilities of MG63 and U2OS cells was evaluated. Both the gain-of- and loss-of-function experiments demonstrated that DEC1 promotes the invasiveness of osteosarcoma cell lines. Overall, these data supported the hypothesis that DEC1 functions as an oncogene in osteosarcoma.

EMT is a dynamic process by which epithelial cells lose their polarity and are converted to present a mesenchymal phenotype, thereby gaining increased motility and invasiveness (32). EMT is considered as a common molecular mechanism promoting tumor metastasis (33). E-cadherin, $\mathrm{N}$-cadherin and vimentin are typical regulators of EMT. In the present study, DEC1 was found to upregulate the mesenchymal markers $\mathrm{N}$-cadherin and vimentin, and downregulate the epithelial marker E-cadherin (34). These results suggest that DEC1 has an inducible effect on EMT in osteosarcoma cell lines, thus contributing to the aggressiveness of osteosarcoma.

$\mathrm{DEC} 1$ is frequently dysregulated in human cancer, and the molecular mechanism of action which regulates its expression is complex. Previous studies have reported that DEC1 can be induced in a cell type-specific manner by various extracellular stimuli, such as hypoxia, growth factors, hormones and cytokines (35-38). DEC1 can also act as a transcriptional factor through interactions with the PI3K/Akt/glycogen synthase kinase $3 \beta$ signaling pathway to promote osteogenic activity and to relieve 1-methyl-4-phenylpyridinium-induced cytotoxicity $(39,40)$. A recent study showed that activation of the Akt/P53/P21 signaling pathway promotes proliferation and migration of human osteosarcoma cells, and activation of the Akt/P53/P21 signaling pathway induced the downregulation of DEC1 (21); however, the direct effect of DEC1 on regulating the Akt/P53/P21 signaling pathway remains unknown. Further studies are required to verify the interaction between DEC1 and the Akt signaling pathway in human osteosarcoma cells.

In conclusion, the present study showed that DEC1 was upregulated in human osteosarcoma tissues and cell lines. Using gain-of- and loss-of-function approaches, the present study suggested that DEC1 may exert its effect on osteosarcoma progression by promoting cell proliferation, adhesion and invasion in vitro. Furthermore, it was found that DEC1 could promote aggressiveness of osteosarcoma cell lines by regulating the expression levels of genes involved in EMT. This preliminary study suggested that $\mathrm{DECl}$ may represent a novel molecular target for the treatment of osteosarcoma. 


\section{Acknowledgements}

Not applicable.

\section{Funding}

No funding was received.

\section{Availability of data and materials}

The data sets generated and analyzed during the study are available from the corresponding author, on reasonable request.

\section{Authors' contributions}

SL and DP conceived, designed and supervised the study. SL, ZY, WZ, XH and CL performed the experiments. SL and ZY analyzed and interpreted the data. SL drafted the manuscript. DP gave final approval of the version to be published. All authors read and approved the manuscript.

\section{Ethics approval and consent to participate}

All patients provided informed written consent, and the study was approved by the Ethics Committee of The Second Xiangya Hospital of Central South University (Changsha, Hunan, China).

\section{Patient consent for publication}

Not applicable.

\section{Competing interests}

The authors declare that they have no competing interests.

\section{References}

1. Bielack SS, Kempf-Bielack B, Delling G, Exner GU, Flege S, Helmke K, Kotz R, Salzer-Kuntschik M, Werner M, Winkelmann W, et al: Prognostic factors in high-grade osteosarcoma of the extremities or trunk: An analysis of 1,702 patientstreated on neoadjuvant cooperative osteosarcoma study group protocols. J Clin Oncol 20: 776-790, 2002.

2. Zhao H, Yao Y, Wang Z, Lin F, Sun Y and Chen P: Therapeutic effect of pirarubicin-based chemotherapy for osteosarcoma patients with lung metastasis. J Chemother 22: 119-124, 2010.

3. He A, Yang X, Huang Y, Feng T, Wang Y, Sun Y, Shen Z and Yao Y: CD133(+) CD44(+) cells mediate in the lung metastasis of osteosarcoma. J Cell Biochem 116: 1719-1729, 2015.

4. Chen J, Ma L and Wei G: Comment on Fu, et al: A systematic review of p53 as a biomarker of survival in patients with osteosarcoma. Tumour Biol 35: 5049-5050, 2014.

5. Shin SH, Jeong HJ, Han I, Cho HS and Kim HS: Osteosarcoma and chondrosarcoma of the shoulder: Site-specific comparative analysis. Orthopedics 36: e179-e185, 2013.

6. Turley H, Wykoff CC, Troup S, Watson PH, Gatter KC and Harris AL: The hypoxia-regulated transcription factor DEC1 (Stra13, SHARP-2) and its expression in human tissues and tumours. J Pathol 203: 808-813, 2004.

7. Kato $\mathrm{Y}$, Kawamoto $\mathrm{T}$, Fujimoto $\mathrm{K}$ and Noshiro $\mathrm{M}$ : DEC1/STRA13/SHARP2 and DEC2/SHARP1 coordinate physiological processes, including circadian rhythms in response to environmental stimuli. Curr Top Dev Biol 110: 339-372, 2014.

8. Sato F, Bhawal UK, Yoshimura T and Muragaki Y: DEC1 and DEC2 crosstalk between circadian rhythm and tumor progression. J Cancer 7: 153-159, 2016.
9. Miyazaki K, Kawamoto T, Tanimoto K, Nishiyama M, Honda H and Kato Y: Identification of functional hypoxia response elements in the promoter region of the DEC1 and DEC2 genes. J Boil Chem 277: 47014-47021, 2002.

10. Yamada K and Miyamoto K: Basic helix-loop-helix transcription factors, BHLHB2 and BHLHB3; Their gene expressions are regulated by multiple extracellular stimuli. Front Biosci 10: 3151-3171, 2005.

11. Marczak MM and Yan B: Circadian rhythmicity: A functional connection between differentiated embryonic chondrocyte-1 (DEC1) and small heterodimer partner (SHP). Arch Biochem Biophys 631: 11-18, 2017.

12. Iwata T, Kawamoto T, Sasabe E, Miyazaki K, Fujimoto K, Noshiro M, Kurihara H and Kato Y: Effects of overexpression of basic helix-loop-helix transcription factor Dec1 on osteogenic and adipogenic differentiation of mesenchymal stem cells. Eur J Cell Boil 85: 423-431, 2006.

13. Wu Y, Sato F, Yamada T, Bhawal UK, Kawamoto T, Fujimoto K, Noshiro M, Seino H, Morohashi S, Hakamada K, et al: The BHLH transcription factor DEC1 plays an important role in the epithelial-mesenchymal transition of pancreatic cancer. Int $\mathrm{J}$ Oncol 41: 1337-1346, 2012.

14. You J,Lin L, Liu Q, Zhu T, Xia K and Su T: The correlation between the expression of differentiated embryo-chondrocyte expressed gene 1 and oral squamous cell carcinoma. Eur J Med Res 19: 21, 2014

15. Liu Y, Miao Y, Wang J, Lin X, Wang L, Xu HT and Wang EH: $\mathrm{DEC} 1$ is positively associated with the malignant phenotype of invasive breast cancers and negatively correlated with the expression of claudin-1. Int J Mol Med 31: 855-860, 2013.

16. Xu Q, Ma P, Hu C, Chen L, Xue L, Wang Z, Liu M, Zhu H, $\mathrm{Xu} \mathrm{N}$ and Lu N: Overexpression of the DEC1 protein induces senescence in vitro and is related to better survival in esophageal squamous cell carcinoma. PLoS One 7: e41862, 2012.

17. Liu Y, Wang L, Lin XY, Wang J, Yu JH, Miao Y and Wang EH: The transcription factor DEC1 (BHLHE40/STRA13/SHARP-2) is negatively associated with TNM stage in non-small-cell lung cancer and inhibits the proliferation through cyclin D1 in A549 and BE1 cells. Tumour Biol 34: 1641-1650, 2013.

18. Jia Y, Hu R, Li P, Zheng Y, Wang Y and Ma X: DEC1 is required for anti-apoptotic activity of gastric cancer cells under hypoxia by promoting Survivin expression. Gastric Cancer 21: 632-642, 2018.

19. Ma W, Shi X, Lu S, Wu L and Wang Y: Hypoxia-induced overexpression of DEC1 is regulated by HIF-1 $\alpha$ in hepatocellular carcinoma. Oncol Rep 30: 2957-2962, 2013.

20. Zheng Q, Wang C, Wang L, Zhang D, Liu N, Ming X, Zhou H, Guli Q and Liu Y: Interaction with SP1, but not binding to the E-box motifs, is responsible for BHLHE40/DEC1-induced transcriptional suppression of CLDN1 and cell invasion in MCF-7 cells. Mol Carcinog 57: 1116-1129, 2018.

21. Zhou L, Yu Y, Sun S, Zhang T and Wang M: Cry 1 regulates the clock gene network and promotes proliferation and migration via the akt/P53/P21 pathway in human osteosarcoma cells. J Cancer 9: 2480-2491, 2018.

22. Livak KJ and Schmittgen TD: Analysis of relative gene expression data using real-time quantitative PCR and the 2(-Delta Delta C(T)) method. Methods 25: 402-408, 2001.

23. Jia YF, Xiao DJ, Ma XL, Song YY, Hu R, Kong Y, Zheng Y, Han SY, Hong RL and Wang YS: Differentiated embryonic chondrocyte-expressed gene 1 is associated with hypoxia-inducible factor $1 \alpha$ and Ki67 in human gastric cancer. Diagn Pathol 8: 37, 2013.

24. Zheng Y, Jia Y, Wang Y, Wang M, Li B, Shi X, Ma X, Xiao D and Sun Y: The hypoxia-regulated transcription factor DEC1 (Stra13, SHARP-2) and its expression in gastric cancer. OMICS 13: 301-306, 2009.

25. Shi XH, Zheng Y, Sun Q, Cui J, Liu QH, Qü F and Wang YS: DEC1 nuclear expression: A marker of differentiation grade in hepatocellular carcinoma. World J Gastroenterol 17: 2037-2043, 2011.

26. Wang W, Reiser-Erkan C, Michalski CW, Raggi MC, Quan L, Yupei Z, Friess H,Erkan M and Kleeff J: Hypoxia inducible BHLHB2 is a novel and independent prognostic marker in pancreatic ductal adenocarcinoma. Biochem Biophys Res Commun 401: 422-428, 2010.

27. Chakrabarti J, Turley H, Campo L, Han C, Harris AL, Gatter KC and Fox SB: The transcription factor DEC1 (stra13, SHARP2) is associated with the hypoxic response and high tumour grade in human breast cancers. Br J Cancer 91: 954-958, 2004.

28. Giatromanolaki A, Koukourakis MI, Sivridis E, Turley H, Wykoff CC, Gatter KC and Harris AL: DEC1 (STRA13) protein expression relates to hypoxia-inducible factor 1-alpha and carbonic anhydrase- 9 overexpression in non-small cell lung cancer. J Pathol 200: 222-228, 2003. 
29. Li Y, Xie M, Yang J, Yang D, Deng R, Wan Y and Yan B: The expression of antiapoptotic protein survivin is transcriptionally upregulated by DEC1 primarily through multiple sp1 binding sites in the proximal promoter. Oncogene 25: 3296-3306, 2006.

30. Thin TH, Li L, Chung TK, Sun H and Taneja R: Stra13 is induced by genotoxic stress and regulates ionizing-radiation-induced apoptosis. EMBO Rep 8: 401-407, 2007.

31. Sgourakis G, Gockel I, Lyros O, Hansen T, Mildenberger P and Lang H: Detection of lymph node metastases in esophageal cancer. Expert Rev Anticancer Ther 11: 601-612, 2011.

32. Nieto MA, Huang RY, Jackson RA and Thiery JP: EMT: 2016. Cell 166: 21-45, 2016.

33. Samant RS and Shevde LA: NMI and EMT. Oncoscience 1: 476-477, 2014.

34. Turley EA, Veiseh M, Radisky DC and Bissell MJ: Mechanisms of disease: Epithelial-mesenchymal transition-does cellular plasticity fuel neoplastic progression? Nat Clin Pract Oncol 5: 280-290, 2008

35. Kon N, Hirota T, Kawamoto T, Kato Y, Tsubota T and Fukada Y Activation of TGF-beta/activin signalling resets the circadian clock through rapid induction of Dec1 transcripts. Nat Cell Boil 10: 1463-1469, 2008.
36. Bhawal UK, Ito Y, Tanimoto K, Sato F, Fujimoto K, Kawamoto T, Sasahira T,Hamada N,Kuniyasu H,ArakawaH, etal:IL-1 $\beta$-mediated up-regulation of DEC1 in human gingiva cells via the Akt pathway. J Cell Biochem 113: 3246-3253, 2012.

37. Yamada K, Kawata H, Shou Z, Mizutani T, Noguchi T and Miyamoto K: Insulin induces the expression of the SHARP-2/Stra13/DEC1 gene via a phosphoinositide 3-kinase pathway. J Boil Chem 278: 30719-30724, 2003.

38. Ivanova AV, Ivanov SV, Danilkovitch-Miagkova A and Lerman MI: Regulation of STRA13 by the von Hippel-Lindau tumor suppressor protein, hypoxia, and the UBC9/ubiquitin proteasome degradation pathway. J Biol Chem 276: 15306-15315, 2001.

39. Zhu Z, Wang YW, Ge DH, Lu M, Liu W, Xiong J, Hu G, Li XP and Yang J: Downregulation of DEC1 contributes to the neurotoxicity induced by MPP(+) by suppressing PI3K/Akt/GSK3 $\beta$ pathway. CNS Neurosci Ther 23: 736-747, 2017.

40. Hu J, Mao Z, He S, Zhan Y, Ning R, Liu W, Yan B and Yang J: Icariin protects against glucocorticoid induced osteoporosis, increases the expression of the bone enhancer DEC1 and modulates the PI3K/Akt/GSK3 $\beta / \beta$-catenin integrated signaling pathway. Biochem Pharmacol 136: 109-121, 2017. 